
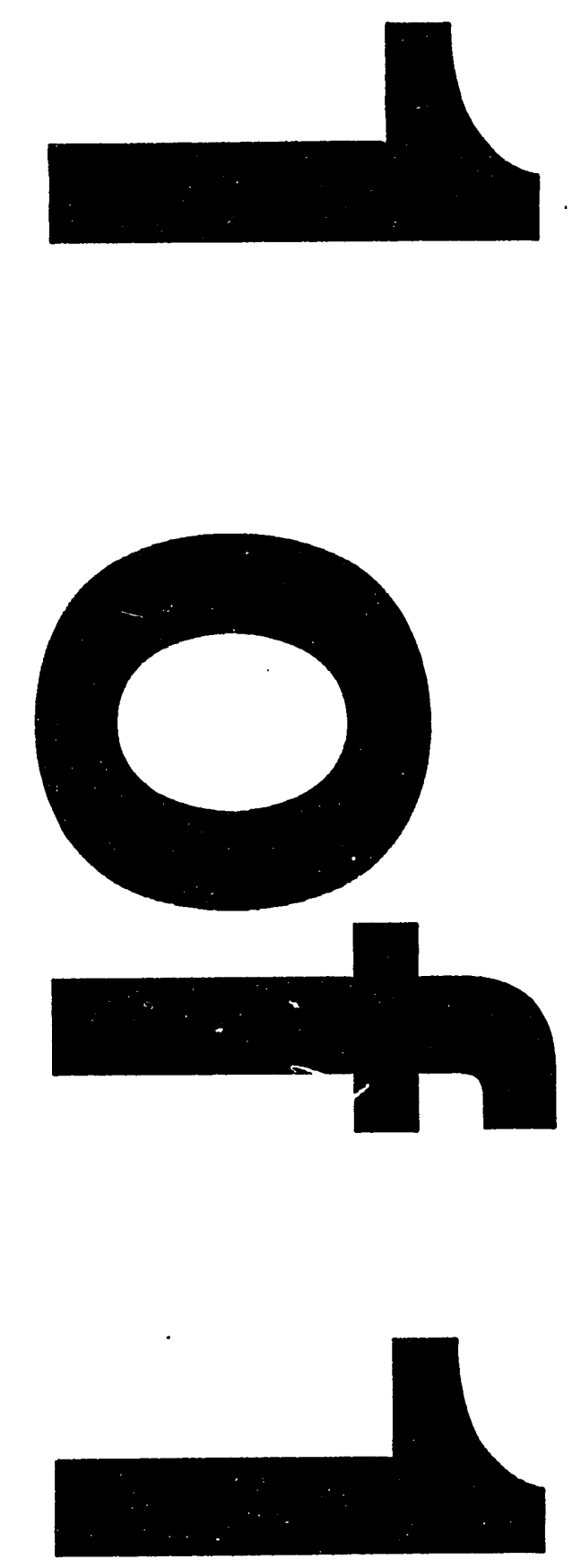
LBL-34289

\title{
THE EFFECTS OF AMORPHOUS LAYER REGROWTH ON CARBON ACTIVATION IN GaAs AND InP
}

\author{
A.J. MOLL, ${ }^{1,2}$ J.W. AGER III, ${ }^{1}$ K.M. YU, ${ }^{1}$ W. WALUKIEWICZ, ${ }^{1}$ AND E.E. HALLER ${ }^{1,2}$ \\ ${ }^{1}$ Center for Advanced Materials, MATERIALS SCIENCES DIVISION \\ Lawrence Berkeley Laboratory \\ University of California \\ Berkeley, California 94720 \\ and \\ 2Department of Materials Science and Mineral Engineering \\ University of California \\ Berkeley, California 94720
}

NOVEMBER 1993

This work was supported by the Director, Office of Energy Research, Office of Basic Energy Sciences, Materials Sciences Division, of the U.S. Department of Energy under Contract No. DE-AC03-76SF00098. A.J. Moll is supported by the Robert N. Noyce Memorial Fellowship from the Intel Foundation. 


\title{
THE EFFECTS OF AMORPHOUS LAYER REGROWTH ON CARBON ACTIVATION IN GaAs AND InP
}

\author{
A.J. Moll, ${ }^{1,2}$ J.W. Ager III, ${ }^{1}$ K.M. Yu, ${ }^{1}$ W. Walukiewicz, ${ }^{1}$ and E.E. Haller ${ }^{1,2}$ \\ ${ }^{1}$ Center for Advanced Materials, Materials Sciences Division, Lawrence Berkeley Laboratory, 1 \\ Cyclotron Road Berkeley, CA 94720 \\ 2 Materials Science and Mineral Engineering, University of California at Berkeley, Berkeley, CA \\ 94720
}

\section{ABSTRACT}

The effect of the $\mathrm{Ga}$ dose on the activation of implanted carbon in $\mathrm{GaAs}$ is determined. The free hole concentration is found to depend on the depth of the amorphous layer created by the $\mathrm{Ga}$ co-implant. Initial results on $\mathrm{C}$ implantation in InP indicate the behavior of $\mathrm{C}$ is very different in InP when compared to GaAs. The role of precipitation in reducing the activation of $\mathrm{C}$ in both GaAs and InP is discussed.

\section{INTRODUCTION}

Ion implantation is a common doping technique in the semiconductor industry. One advantage of ion implantation is that the dopant concentration profile can be well predicted. ${ }^{1}$ In practice, several factors can change the active dopant concentration profile from theoretical predictions. Two of the most prominent factors are diffusion and limited activation of the implanted dopant. Diffusion occurs during high temperature annealing which is required to repair the radiation damage created during the implantation process. Limited activation results from dopant ions not residing in substitutional lattice positions or loss of free carriers to compensating defects in the implanted layer. In compound semiconductors, the additional effect of the dopant atom occupying the incorrect site can also decrease the activation.

The reported diffusion coefficient of carbon in GaAs is much lower than that of the group II acceptors. ${ }^{2}$ Howe er, when implanted into GaAs alone it has very low activation, less than $10 \%$ at doses greater than $1 \times 10^{14} \mathrm{~cm}^{-2} .^{3} \mathrm{Ga}$ co-implants have been shown to increase the $\mathrm{C}$ activation up to $65 \% .4$ In previous work, we have shown that the increase in activation is due to two effects: stoichiometry and damage. ${ }^{5}$ The Ga co-implant increases the amount of radiation damage in the lattice and this allows the $C$ to occupy an As site. Second, the Ga co-implant naaintains the stoichiometry in the implanted layer minimizing the number of compensating native defects.

In this paper, we address several additional questions. Can the activation of $\mathrm{C}$ in $\mathrm{GaAs}$ be increased even further by changing the implantation conditions? How does the regrowth of an amorphous layer affect $\mathbf{C}$ in GaAs? What is the lattice position of the inactive $C$ ? We report initial work on $\mathrm{C}$ implantation in InP and compare the findings with our results in GaAs. 


\section{EXPERIMENTAL}

Semi-insulating (100) LEC GaAs or Fe doped InP substrates were solvent cleaned, etched in $12 \mathrm{M} \mathrm{HCl}$ for 1 minute ( $\mathrm{GaAs}$ only), and rinsed in de-ionized water before implantation. Singly ionized $C$ ions were implanted into all of the substrates simultaneously at an energy of $40 \mathrm{keV}$ and a dose of $3.5 \times 10^{14} \mathrm{~cm}^{-2}$. Following implantation of $\mathrm{C}$, the co-implant was performed for individual samples. The dose and energy of the co-implant are given in Table I. The wafers were tilted $7^{\circ}$ off the [100] axis during implantation to prevent channeling. The co-implants were performed with the wafer held at room temperature or with the sample holder cooled with liquid nitrogen. The substrate temperature during low tempsiature implantations was held at $108 \mathrm{~K}$. The dose rate for the $\mathrm{Ga}$ implantations was kept very low, $<0.1 \mu \mathrm{A} / \mathrm{cm}^{2}$. Following implantation, the samples were annealed in flowing forming gas $\left(90 \% \mathrm{~N}_{2} / 10 \% \mathrm{H}_{2}\right)$ at $950^{\circ} \mathrm{C}$ for $10 \mathrm{~s}$ (GaAs) or $850^{\circ} \mathrm{C}$ for $10 \mathrm{~s}$ (InP) using a proximity cap.

Allo:ed contacts of In: $\mathrm{Zn}$ for $\mathrm{GaAs}$ and In:Sn for InP were formed at $250^{\circ} \mathrm{C}$ on $8 \times 8 \mathrm{~mm}^{2}$ pieces of each sample. Carrier concentration, mobility, and resistivity as a function of temperature were determined by van der Pauw geometry Hall effect measurements. The activation (or electrical activity) is then determined by dividing the sheet free carrier concentration (holes) by the implanted dose. Free carrier concentration as a function of depth was measured by an electrochemical capacitance voltage profiler.

The amount of structural damage caused by the implantation was characterized by channeling Rutherford backscattering spectrometry (RBS) using $1.95 \mathrm{MeV} \mathrm{He}^{+}$ions aligned along the $\langle 111\rangle$ or $\langle 110\rangle$ direction. Raman spectra were collected with $2 \mathrm{~cm}^{-1}$ resolution at room temperature in the $z(x, y) \bar{z}$ pseudo-backscattering geometry. The $488 \mathrm{~nm}(2.54 \mathrm{eV})$ line of an $\hat{A}$ ion laser was used.

\section{RESULTS AND DISCUSSION}

The effect of the Ga co-implant dose on the depth of the amorphous layer in $\mathrm{C}$ implanted GaAs is shown in Fig. 1. As the co-implant dose increases, the depth of the amorphous layer as measured by channeling RBS also increases. At a sufficiently high dose, the depth of the

Table I. Parameters for implantations in GaAs used in this study.

\begin{tabular}{|c|c|c|}
\hline Implant Parameters & Co-implant Parameters & Temperature \\
\hline $\begin{array}{l}C: 40 \mathrm{keV} \\
\vdots .5 \times 10^{14} \mathrm{~cm}^{-2} \\
\text { for all samples }\end{array}$ & $\begin{array}{l}\text { none } \\
\text { Ga: } 180 \mathrm{keV}, 7 \times 10^{13} \mathrm{~cm}^{-2} \\
\text { Ga: } 180 \mathrm{keV}, 7 \times 10^{13} \mathrm{~cm}^{-2} \\
\text { Ga: } 180 \mathrm{keV}, 3.5 \times 10^{14} \mathrm{~cm}^{-2} \\
\text { Ga: } 180 \mathrm{keV}, 3.5 \times 10^{14} \mathrm{~cm}^{-2} \\
\text { Gd: } 180 \mathrm{keV}, 7 \times 10^{14} \mathrm{~cm}^{-2} \\
\text { Ga: } 180 \mathrm{keV}, 7 \times 10^{14} \mathrm{~cm}^{-2}\end{array}$ & $\begin{array}{l}\text { RT } \\
\text { LN } \\
\text { RT } \\
\text { LN } \\
\text { RT } \\
\text { LN }\end{array}$ \\
\hline
\end{tabular}


amorphous layer will saturate. The $\mathrm{Ga}$ dose of $7 \times 10^{14} \mathrm{~cm}^{-2}$ at $180 \mathrm{keV}$ is not high enough for this to have occurred. From our work on Ge implanted into GaAs, the dose at which the damage saturates is approximately $2 \times 10^{15} \mathrm{~cm}^{-2}$ when the implantation energy is $180 \mathrm{keV}$. 6 The amorphous layer is consistently deeper for co-implants performed at low temperature relative to implants performed at room temperature due to difference in dynamic annealing of $\mathrm{GaAs}$ at low and room temperature.

The sample which was implanted with $\mathrm{Ga}$ at a dose of $7 \times 10^{13} \mathrm{~cm}^{-2}$ at room temperature is heavily damaged, but it does not become amorphous. This is indicated in Fig. 1 as an amorphous layer of zero thickness. The Ga co-implant of the same dose $\left(7 \times 10^{13} \mathrm{~cm}^{-2}\right)$ performed at low temperature creates an amorphous layer $90 \mathrm{~nm}$ thick. The amorphous layer created by implantation at low temperature regrows more perfectly than the implanted layer which is heavily damaged but not amorphous. Similar behavior has been observed with detailed solid phase epitaxy studies in $\mathrm{Si}$ and Ge.7,8

Figure 2 shows the effect of the co-implant dose on the sheet free hole concentration. As the dose increases the hole concentration increases. Samples which were co-implanted at low temperature have consistently higher sheet carrier concentrations. Considering the effect of the dose and temperature of the co-implant, it is evident that a correlation exists between thickness of the amorphous layer and the activation of implanted $\mathrm{C}$.

To address the issue of the mechanism responsible for the increase in activation, let us compare the samples implanted with $\mathrm{Ga}$ at a dose of $7 \times 10^{14} \mathrm{~cm}^{-2}$. The sample implanted at room temperature has an amorphous layer $130 \mathrm{~nm}$ deep. The sheet free hole concentration after annealing in this sample is $2.2 \times 10^{14} \mathrm{~cm}^{-2}$. In the sample implanted at low temperature, the amorphous layer is $150 \mathrm{~nm}$ deep, and the sheet free hole concentration after annealing is $3 \times 10^{14}$ $\mathrm{cm}^{-2}$. The additional $8 \times 10^{13} \mathrm{~cm}^{-2}$ free holes cannot be merely additional $\mathrm{C}$ atoms which occupy substitutional sites in the region between 130 and $150 \mathrm{~nm}$ below the surface. The average concentration of $C$ in this region is $1 \times 10^{19} \mathrm{~cm}^{-3}$ which then corresponds to $2 \times 10^{13} \mathrm{~cm}^{-2}$ free holes if all $\mathrm{C}$ atoms in this region contribute a free hole in one sample but not in the other.

Consider the concentration of holes as a function of depth shown in Fig. 3 for the sample co-implanted with $\mathrm{Ga}$ at low temperatures at a dose of $7 \times 10^{13} \mathrm{~cm}^{-2}$. The depth of the amorphous layer in this sample is $90 \mathrm{~nm}$ before annealing. The amorphous to crystalline interface is near the peak of the $\mathrm{C}$ concentration profile. No significant change in the free hole

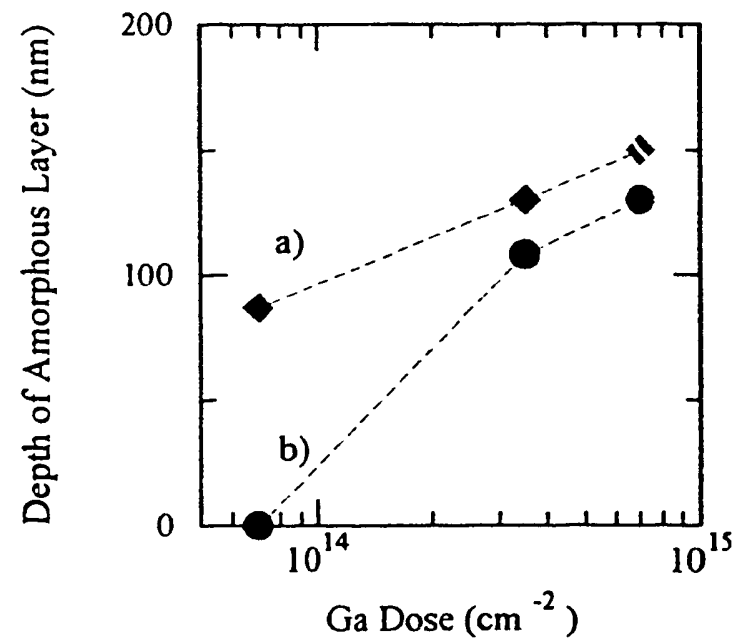

Figure 1. Depth of the amorphous layer as a function of $\mathrm{Ga}$ co-implant dose for co-implant performed at a) $108 \mathrm{~K}$ and b)room temperature.

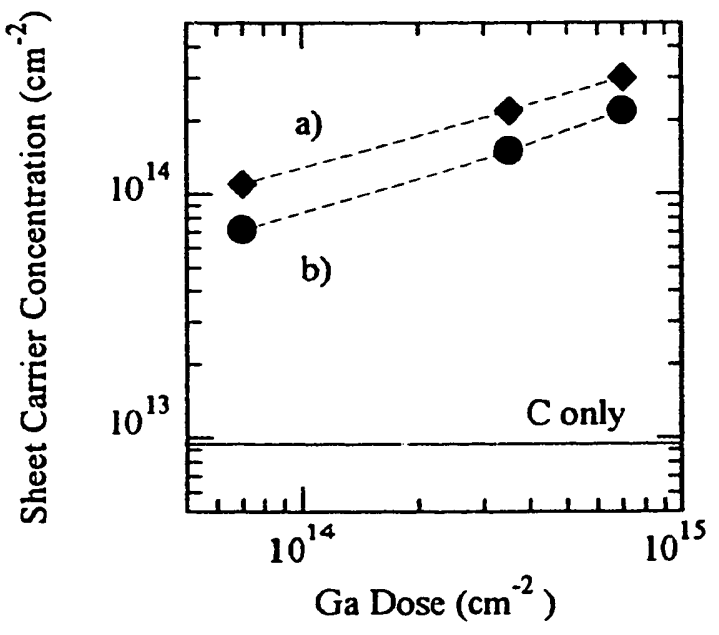

Figure 2. The sheet free hole concentration as a function of the Ga co-implant dose for co-implant performed at a) $108 \mathrm{~K}$ and b) room temperature. 
concentration occurs at this depth. Therefore, the increase in free carriers as the amorphous layer increases in depth is due to an overall increase in damage density as the dose increases or when the implant is performed at low temperature.

The activation we attain in this study is higher than any activation reported in the literature of $\mathrm{C}$ implanted into GaAs. However, other studies have been performed with higher doses of $\mathrm{C}$ at similar energies. The peak concentration of free holes is similar to the peak concentration achieved in other studies 3 (approximately $2 \times 10^{19} \mathrm{~cm}^{-3}$ ). This concentration is a larger percentage of the implanted $\mathrm{C}$ due to the lower dose used in this study compared to others. We suggest that at annealing temperatures of between 800 and $950{ }^{\circ} \mathrm{C}$ there is a maximum concentration of holes attainable in $\mathrm{C}$ doped GaAs which is the solid solubility limit of $\mathrm{C}$ in GaAs at these temperatures. In very heavily doped samples with $\mathrm{p}>5 \times 10^{19} \mathrm{~cm}^{-3}$, high temperature annealing reduces the free hole concentration to between 2 to $4 \times 10^{19} \mathrm{~cm}^{-3}$. The final hole concentration is independent of the original hole or $\mathrm{C}$ concentration in the material before annealing for such highly doped samples.

Several possibilities have been suggested for the location of the inactive $C$ in the implanted samples with low activation and also in annealed epilayers, including self compensation, interstitial $C$, and $C$ precipitation. In Fig. 4, we show the Raman spectra from the sample implanted with $\mathrm{C}$ only which has an activation of only $3 \%$. The broad features centered at 1585 $\mathrm{cm}^{-1}$ and $1355 \mathrm{~cm}^{-1}$ are assigned to $\mathrm{sp}^{2}$ bonded $\mathrm{C}$. These peaks are also present in heavily doped MOMBE epilayers $\left([\mathrm{C}]=6 \times 10^{20} \mathrm{~cm}^{-3}\right)$ which have been annealed at $850{ }^{\circ} \mathrm{C}$ for 3 hours. The ratio of the peak heights indicate that the domain size of the $\mathrm{sp}^{2}$ bonded $\mathrm{C}$ is $5 \mathrm{~nm}$. Full details of this study are reported elsewhere. ${ }^{9}$ The precipitation of $\mathrm{C}$ could account for the major portion of the inactive $\mathbf{C}$ in both implanted layers and annealed epilayers.

We now provide a qualitative view of $\mathrm{C}$ implantation and the effect of the $\mathrm{Ga}$ co-implant. The $\mathrm{Ga}$ co-implant has two effects on the $\mathrm{C}$ activation. First, it creates additional damage in the lattice which allows the $C$ to substitute for an As atom. Second, $G$ a has a stoichiometric effect on the $C$ activation. By maintaining the stoichiometry of the implanted layer, the number of compensating native defects is reduced which increases the number of free holes for conduction. Also, $\mathrm{C}$ has been shown to diffuse more rapidly in an As rich environment. ${ }^{10} \mathrm{C}$ implanted alone results in a As rich implanted layer which increases the diffusion of $\mathbf{C}$ and therefore increases the

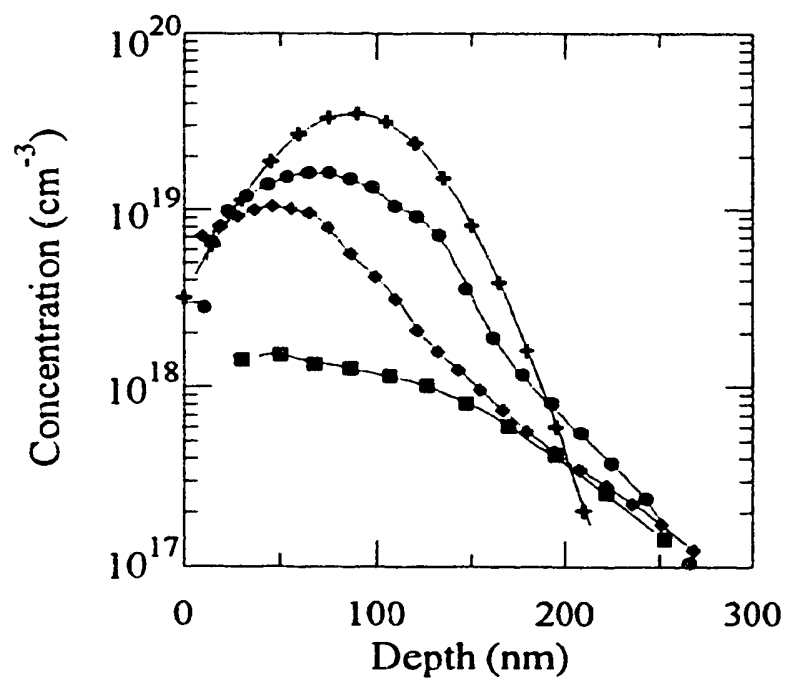

Figure 3. Free hole concentration as a function of depth for $\square \mathrm{C}$ only, $\triangle \mathrm{C}+\mathrm{Ga}\left(7 \times 10^{13} \mathrm{~cm}^{-2} \mathrm{LN}\right)$, $-\mathrm{C}+\mathrm{Ga}\left(7 \times 10^{14} \mathrm{~cm}^{-2} \mathrm{LN}\right)$, and + predicted $\mathrm{C}$ profile.

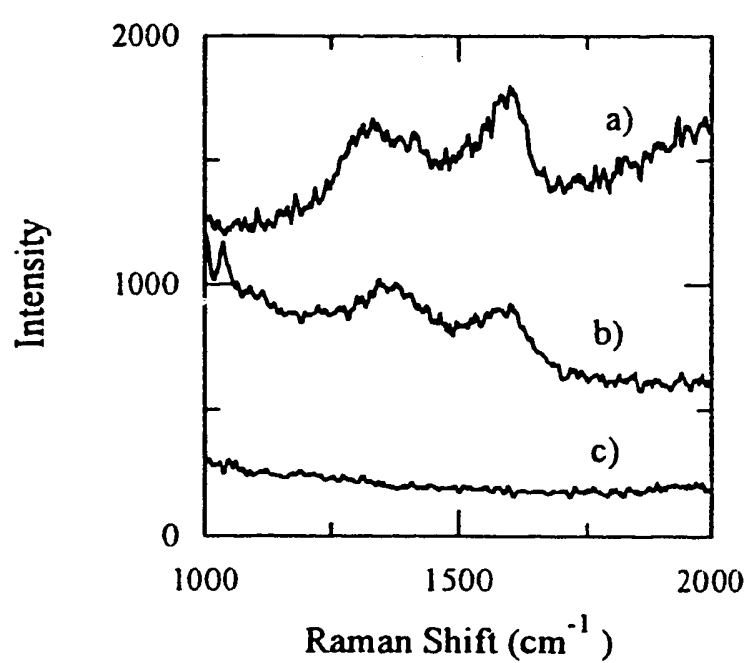

Figure 4. Raman spectra of carbon precipitates. a) GaAs: $C$ only implantation, annealed, b) InP: $\mathrm{C}$ only implantation, annealed, c) $\mathrm{GaAs}$, not implanted, annealed. 
Table II. Implant parameters and results for $\mathrm{C}$ implanted in InP.

\begin{tabular}{|c|c|c|c|c|c|c|}
\hline $\begin{array}{l}\text { Implant } \\
\text { Parameters }\end{array}$ & & $\begin{array}{l}\text { Co-implant } \\
\text { Parameters }\end{array}$ & & $\begin{array}{l}\text { Amorphous } \\
\text { Layer thickness } \\
\text { (nm) (RBS) }\end{array}$ & $\begin{array}{l}\text { Sheet Free } \\
\text { Carrier Conc. } \\
\left(\mathrm{cm}^{-2}\right)\end{array}$ & Activation \\
\hline $\begin{array}{l}C: 40 \mathrm{keV} \\
3.5 \times 10^{14} \mathrm{~cm}^{-2}\end{array}$ & $\mathrm{RT}$ & none & & 0 & $1.7 \times 10^{13}$ & $5 \%$ \\
\hline $\begin{array}{l}C: 40 \mathrm{keV} \\
3.5 \times 10^{14} \mathrm{~cm}^{-2}\end{array}$ & RT & $\begin{array}{l}\text { P: } 90 \mathrm{keV} \\
3.5 \times 10^{14} \mathrm{~cm}^{-2}\end{array}$ & $\mathbf{R T}$ & 160 & $7.6 \times 10^{10}$ & $0 \%$ \\
\hline $\begin{array}{l}C: 40 \mathrm{keV} \\
3.5 \times 10^{14} \mathrm{~cm}^{-2}\end{array}$ & RT & $\begin{array}{l}\text { P: } 90 \mathrm{keV} \\
3.5 \times 10^{14} \mathrm{~cm}^{-2}\end{array}$ & $\mathbf{L N}$ & 170 & $2.7 \times 10^{13}$ & $8 \%$ \\
\hline
\end{tabular}

likelihood of precipitation. The $\mathrm{Ga}$ co-implant therefore impedes diffusion and hence the precipitation of the $C$, again increasing the activation. Finally, there appears to be a solid solubility limit near $5 \times 10^{19} \mathrm{~cm}^{-3}$ for $\mathrm{C}$ in GaAs at temperatures greater than $650^{\circ} \simeq$ which will affect the activation.

Initial work on $\mathrm{C}$ implanted in InP indicate its behavior is significantly different than the behavior of $\mathrm{C}$ in GaAs. $\mathrm{C}$ substitutes for In and acts as an donor however its activation is very low and co-implants seem to have little effect. ${ }^{11}$ The electrical data for our InP samples implanted with $C$ is shown in Table II. The $P$ co-implant seems to have little effect on the activation, and the activation is very low in all samples. Raman spectra (Fig. 4) indicate that $C$ precipitates are also present in this material.

\section{CONCLUSIONS}

Increasing the amount of damage in the implanted layer increases the activation of implanted $\mathrm{C}$ in GaAs. The same behavior is not seen for $\mathrm{C}$ implanted into InP. In both cases, precipitation is responsible at least in part for reduced activation.

\section{ACKNOWLEDGMENTS}

The authors would like to thank Kevin Roderick for his assistance in implantation and E.R. Weber, S. Nozaki, M. Konagai, and K. Takahashi for providing the C-doped epilayers. This work was supported by The Director, Office of Energy Research, Office of Basic Energy Sciences, Materials Science Division of the U.S. Department of Energy under Contract No. DEAC03-76SF00098. A.J. Moll is supported by the Robert N. Noyce Memorial Fellowship from the Intel Foundation. 


\section{REFERENCES}

1. J. Lindhard, M. Scharff and H.E. Schiott, Kfl. Danske. Videnskab. Selskab. Mat.-Fys. Medd. 33, (1963).

2. B.T. Cunningham, L.J. Guido, J.E. Baker, J.S. Major Jr., N. Holonyak Jr. and G.E. Stillman, Appl. Phys. Lett. 55, 687 (1989).

3. S.J. Pearton and C.R. Abernathy, Appl. Phys. Lett. 55, 678 (1989).

4. A.J. Moll, K.M. Yu, W. Walukiewicz, W.L. Hansen and E.E. Haller, Appl. Phys. Lett. 60, 2383 (1992).

5. A.J. Moll, J.W. Ager III, K.M. Yu, W. Walukiewicz and E.E. Haller, J. Appl. Phys. 74, (1993).

6. K.M. Yu and A.J. Moll, unpublished

7. L. Csepregi, R.P. Kullen and J.W. Mayer, Solid State Commun. L1, 1019 (1977).

8. L. Csepregi, E.F. Kennedy, J.W. Mayer and T.W. Signon, J. Appl. Phys. 49, 3906 (1978).

9. A.J. Moll, E.E. Haller, J.W. Ager III and W. Walukiewicz, submitted to Appl. Phys. Lett. (1993).

10. H.M. You, T.Y. Tan, U.M. Göseie, S.T. Lee, G.E. Höfler, K.C. Hsieh and N. Holonyak Jr., J. Appl. Phys. 74, 2450 (1993).

11. S.J. Pearton, U.K. Chakrabarti, C.R. Abernathy and W.S. Hobson, Appl. Phys. Lett. 55, 2014 (1989). 


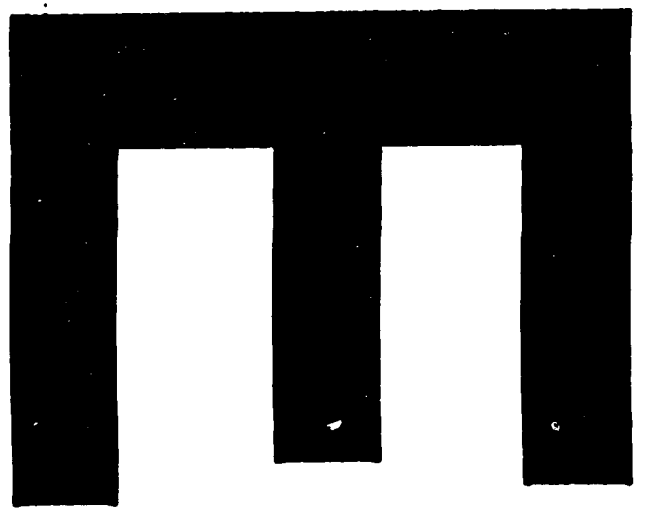

$\omega$
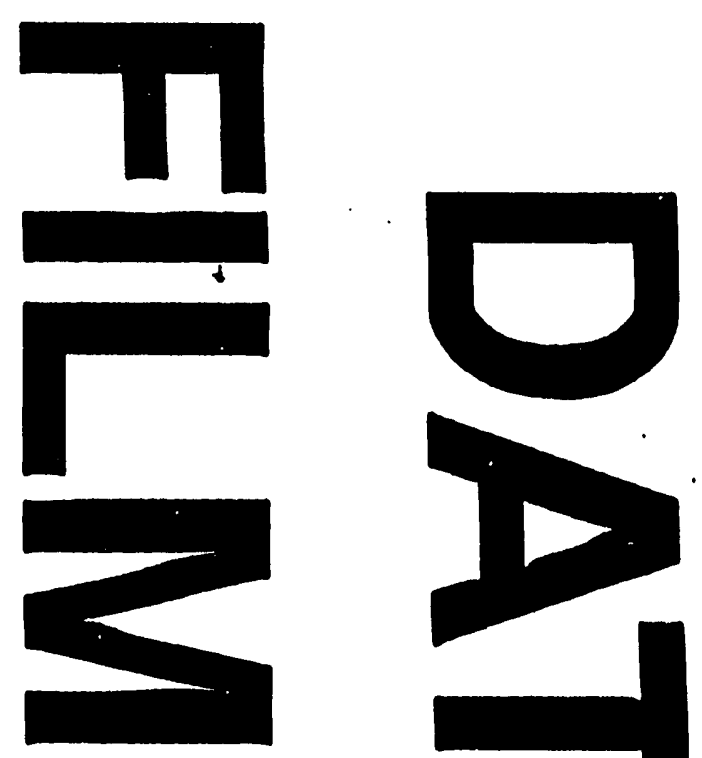

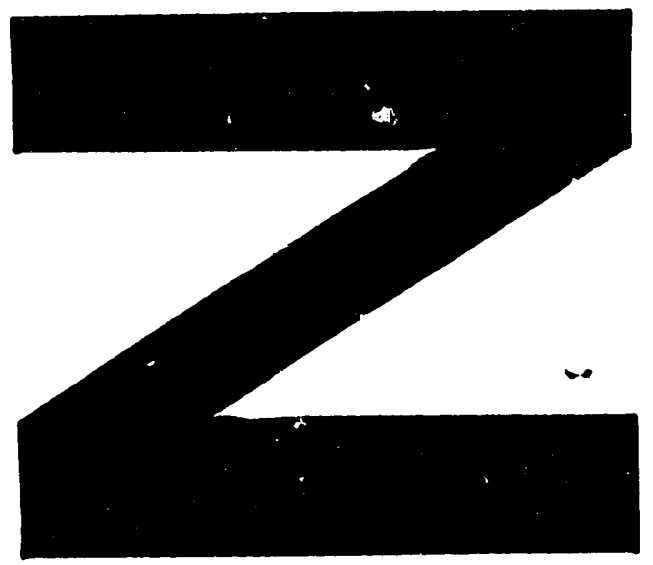

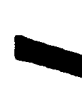
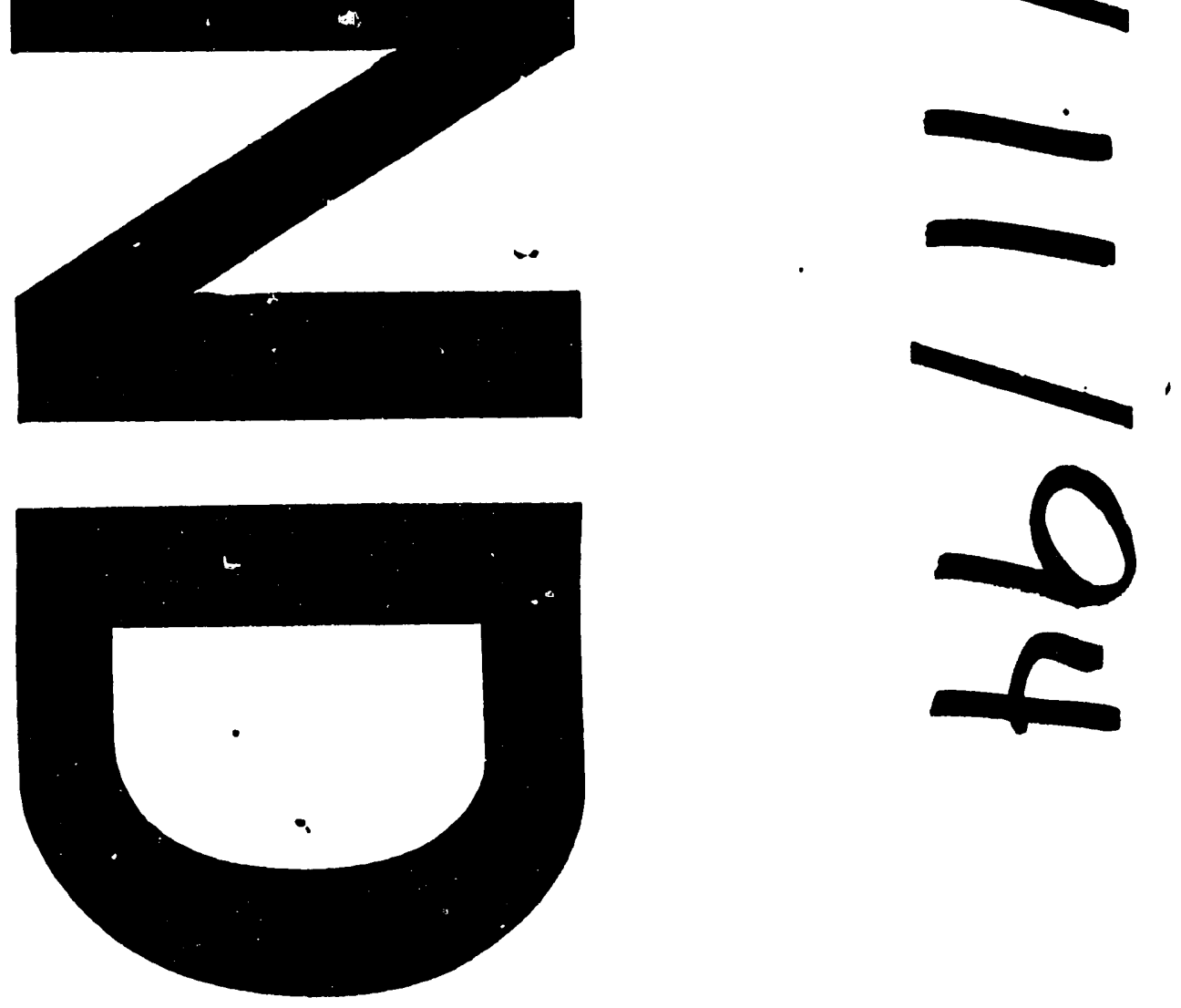

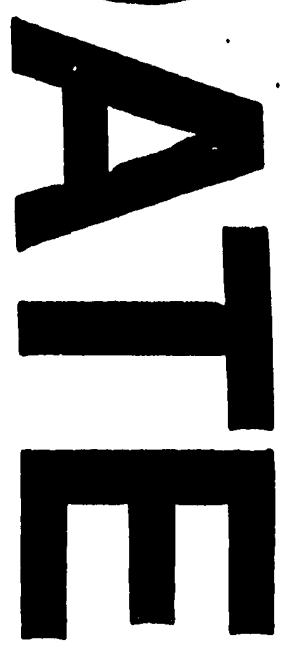

